\title{
La complejidad de la imagen de los destinos de costa: una conceptualización a partir del estudio de Menorca
}

\author{
Alfons Xavier Méndez Vidal* \\ Ajuntament des Mercadal. Institut Menorquí d'Estudis (España)
}

\begin{abstract}
Resumen: En este artículo se intenta conceptualizar la imagen de los destinos de costa a partir del análisis de un lugar concreto, Menorca. Se estudia tanto el contenido de las imágenes como su significado para desentrañar su función en la configuración de la imagen turística, así como el papel que juegan en la apropiación de los arquetipos universales. Se confrontan dos tipos de imágenes: carteles y folletos públicos, por un lado, y guías turísticas, por otro, con un enfoque diacrónico. Como resultado, los destinos de costa se muestran como un producto complejo en el que junto a sus obvias implicaciones asociadas al concepto de sol y playa, emerge un importante aspecto paisajístico, y donde también son relevantes los núcleos de población que a él se asoman. De este modo la imagen proyectada no se puede desligar de la imagen percibida por los turistas.
\end{abstract}

Palabras Clave: Turismo de costa; Imagen del destino; Análisis del contenido; Imagen proyectada; Menorca.

The complexity of the image of coastal destinations: a conceptualization from the study of Menorca

Abstract: In this article, we try to conceptualize the image of coastal destinations based on the analysis of a specific place, Menorca. Both the content of the images and their meaning are studied to unravel their function in the configuration of the tourist image, as well as the role they play in the appropriation of universal archetypes. Two types of images are confronted: posters and public leaflets, on the one hand, and tourist guides, on the other, with a diachronic approach. As a result, coastal destinations are shown as a complex product in which, along with its obvious implications associated with the concept of sun and beach, an important landscape aspect emerges, and where their population centres are also relevant. In this way the projected image cannot be separated from the image perceived by tourists.

Keywords: Coastal tourism; Destination image; Content analysis; Projected image; Minorca.

\section{Introducción: La imagen de los destinos de costa. Menorca}

El turismo ligado al litoral aparece en el siglo XVIII en las costas del mar del Norte y en la centuria siguiente alcanzó el mar Mediterráneo, en lo que se ha venido a denominar primera y segunda periferias turísticas (Gormsen, 1997). En los dos casos se trataba de viajeros elitistas. En el siglo XX emerge el turismo de costa moderno, vinculado directamente con la democratización del ocio (Cirer, 2012). Las playas calientes, con su combinación de baños de mar y de sol, irrumpirán en los felices veinte y transformarán el concepto del viaje, que pasa de ser el refugio frente a los crudos fríos invernales al disfrute del sol del sur (Larrinaga, 2015). El fenómeno se reforzará después de la II Guerra Mundial, cuando el transporte aéreo y la invención del paquete turístico abaraten el coste del veraneo de manera asombrosa. De este modo, en los años setenta, turismo llega a ser casi sinónimo de sol y playa. A pesar de que en las décadas siguientes los factores de atracción turística se irán diversificando, actualmente sigue siendo la principal motivación de viaje a escala mundial.

Como todo destino turístico, los de costa aparecen con una imagen determinada. Sin embargo, a pesar de su importancia, los estudios no son excesivamente numerosos ni se refieren a los clásicos lugares

Ajuntament des Mercadal. Institut Menorquí d’Estudis (España); E-mail: alfons.mendez@gmail.com; https://orcid. org/0000-0002-3793-4099 
de veraneo (Anjos y Pereira, 2017). Además, el enfoque predominante ha sido el estudio de la imagen percibida por los turistas. La imagen proyectada por los destinos turísticos es relevante tanto por su capacidad de influir en el la decisión de visita de los turistas, como por su efecto sobre la competitividad de los destinos (Camprubí, Guía y Comas, 2014).

Por otra parte, estos enclaves han experimentado en primera línea las transformaciones del negocio turístico. A diferencia de la imagen general de España, que impregna la de la mayoría de regiones y ciudades, la tradición romántica (Poutet, 1995), aquí es débil y, en la etapa formativa la costa tiene que inventar su imagen. Esta invención nunca parte de cero, máxime en el Mediterráneo, cargado de historia, patrimonio y naturaleza por los cuatro costados (Pemble, 1987), pero tampoco lo será en la mayoría de los enclaves del litoral, dotados de un paisaje potente y sociedades pintorescas a los ojos del turista y en multitud de casos, con un patrimonio sino monumental, original. Asimismo, la temprana puesta en valor del sol, el calor y el mar exigirá a los destinos que reestructuren su iconografía.

Analizar los cambios en la imagen proyectada a lo largo del tiempo es de sumo interés para discernir su adaptación a las nuevas condiciones de los mercados turísticos. A pesar de su interés para una comprensión cabal del producto turístico, los estudios diacrónicos de la imagen turística son escasos y no se refieren a períodos excesivamente dilatados de tiempo (Descamps y Camprubí, 2018).

Menorca es un buen punto de partida para estudiar el nacimiento y evolución de la imagen de los destinos de costa. Desde el siglo XX, el argumento marítimo asociado a un clima moderado ha sido la motivación principal de las personas que se desplazaban a la isla. Históricamente, su elemento más distintivo son los monumentos megalíticos, de dimensiones comedidas y poco aptos para el turismo de masas. Por otro lado, algunas de sus playas y la costa tienen un encanto particular, ${ }^{1}$ lo cual permite considerarla como un ejemplo típico del Mediterráneo.

En 2017 recibió un total de 1.462.554 turistas, 968.912 extranjeros. ${ }^{2}$ En esta fecha su población era de 91.170 habitantes que se reparten en los $702 \mathrm{~km}^{2}$ de extensión de la isla. Las dos mayores poblaciones se sitúan en sendos puertos ubicados al este (Mahón) y oeste (Ciudadela), pero en sus $299 \mathrm{~km}$ de perímetro marítimo (más que la provincia de Tarragona), ${ }^{3}$ se distribuyen cincuenta núcleos turísticos, la mayoría de pequeñas dimensiones, donde conviven establecimientos hoteleros, apartamentos y chalets. El número de lugares aptos para el baño es muy elevado (una guía inglesa de 1965 hablaba de ciento veinte playas).

El objetivo de este trabajo es conceptualizar la imagen turística proyectada por los destinos de costa, atendiendo a sus particularidades en relación a los destinos urbanos o ámbitos geográficos más amplios, como las regiones, comunidades autónomas o países. Se utiliza la isla de Menorca como caso de estudio. Asimismo, se analiza el proceso de formación de su imagen turística a lo largo de un siglo, desde su nacimiento como enclave turístico. Para ello se utilizan los medios de difusión general de esta, tanto públicos (carteles y folletos), como privados (guías turísticas) con el objeto de comprender hasta qué punto los agentes privados se alinean con la imagen proyectada por los organismos de promoción turística o, a la inversa si el sector público se acomoda a las expectativas del sector privado, más sensible a la imagen percibida por los visitantes.

\section{La imagen de los destinos turísticos}

La imagen de los destinos turísticos constituye una línea de investigación que atrae una atención académica creciente, debido a que su papel central en la elección del lugar al cual se desplazan los turistas lo hace uno de los factores más determinantes en el desarrollo de los puntos de atracción turística (Hunt, 1975). La multidimensionalidad del fenómeno ha propiciado que haya sido sujeto de diversas aproximaciones conceptuales basadas en diferentes perspectivas (Galí y Donaire, 2005).

Una parte de estos estudios se ha centrado en la imagen percibida por los turistas, normalmente en el marco de la elección del destino por el consumidor (Echtner y Ritchie, 1991). Existe un notable consenso en que la imagen es el conjunto de creencias, ideas, impresiones y percepciones que las personas se construyen de un lugar (Crompton, 1979), (Kotler, Haider y Rein, 1994) o, expresado de otra manera, la representación mental de las creencias, los sentimientos y la impresión general del individuo sobre el destino turístico (Baloglu y McCleary, 1999).

De este modo se distinguen tres grandes componentes de la imagen percibida por el turista (Moutinho, 1987; Garner, 1993; Baloglu y Brinberg, 1997): el cognitivo, que se refiere a los atributos físicos del lugar, el afectivo, relacionado con los sentimientos que este provoca en el visitante y el conativo, que se 
refiere a la manera en que actúa, en base a sus conocimientos y sentimientos. Así mismo, el contenido de la imagen incluye factores tanto de carácter funcional (directamente observables), como de tipo psicológico (no observables) y en ambos casos puede tratarse tanto de características individuales como de impresiones de tipo general u holístico (Echtner y Ritchie, 1991).

De este modo se ha generado un corpus ya asentado sobre el proceso de formación de la imagen por parte del consumidor, el cual se fundamenta en una perspectiva psicológica (Goodall, 1991; Gartner, 1993), y que define una serie de etapas en la toma de decisiones hasta el momento del viaje y la reevaluación de la imagen en función de la experiencia (Gunn, 1988), así como los factores que influyen en la conducta del consumidor (Baloglu y McCleary, 1999). En este sentido, cabe realizar una importante distinción entre la percepción a priori, in situ y a posteriori que tiene el visitante de un destino (Galí y Donaire, 2003), puesto que los mensajes más apropiados para influir en la conducta del consumidor son diferentes en un caso u otro (Fakeye \& Crompton, 1991).

Las imágenes anticipadas que suscitan el interés por viajar generan en el turista una mirada selectiva que funciona como una verdadera guía durante el viaje, determinando qué elementos son fundamentales para visitar, mirar o fotografiar (Urry, 1990b). De hecho, las imágenes definen lo que es bello, lo que debería experimentarse y con quien deberíamos interactuar (Dann, 1996). Quizá por ello, para el éxito de los destinos turísticos es vital que exista una cierta correspondencia entre la imagen previa y la experiencia del viaje, para que las expectativas del visitante no se vean defraudadas (Ashworth, 1991).

La segunda línea de trabajo se centra en la imagen que proyectan los destinos turísticos y se asienta, por tanto, en un enfoque sociológico, antropológico o geográfico. En este contexto, se enfatiza el hecho de que la imagen al mismo tiempo que constituye una experiencia subjetiva, se trata de una construcción social. Los estudios que combinan ambos enfoques (imagen percibida y proyectada), aunque escasos, son muy sugerentes (Paül, 2018).

La imagen proyectada no es la realidad, sino la representación figurada de ésta que es producida en contextos sociales y conformada históricamente (Morgan y Pritchard, 2001). Desde este punto de vista se pueden distinguir dos tipos de imágenes (Gunn, 1988, Mansfeld, 1992): orgánicas o informales, generadas por fuentes de comunicación no comerciales, como los medios de comunicación generalistas, las opiniones de amigos y la educación recibida, e inducidas o formales, que son transmitidas deliberadamente por los folletos, carteles, guías turísticas y agencias de viajes para atraer a los turistas potenciales.

Como la experiencia turística es fundamentalmente visual (Urry, 1990; Nelson, 2005), la fotografía está íntimamente ligada a ésta (Garrod, 2009), hasta el punto de que se puede defender que las representaciones visuales transforman de manera funcional los lugares en destinos turísticos (Hunter, 2008). Las fotografías, al enseñarnos un nuevo código visual, alteraran y amplían nuestras nociones de lo que vale la pena mirar y lo que tenemos derecho a observar (Sontag, 2002).

Las imágenes inducidas, por su parte, pueden ser estudiadas utilizando dos grandes enfoques. Aunque las primeras aproximaciones al fenómeno atendían a aspectos semióticos, considerando el significado de las imágenes, que se consideran signos o símbolos (Barthes, 1957; Uzzel, 1984; Urry, 1990b), modernamente son más frecuentes los análisis del contenido (Buck, 1977; Dann, 1988), puesto que de esta manera las imágenes son más fáciles de sistematizar. Algunos autores integran estas dos perspectivas para intentar captar todos los aspectos de la imagen del destino (Galí y Donaire, 2005; Hunter, 2008; Hernández, 2008), hasta el punto de ofrecer una definición que los engloba a ambos: "el análisis del contenido es un método de investigación observacional utilizado para evaluar de manera sistemática el contenido real y simbólico de cualquier medio o forma de comunicación" (Kolbe y Burnett, 1991)

Es interesante tener en cuenta la distinción entre las imágenes según su generalidad y forma de generación (Miossec, 1977; Gunn 1988). Así hallamos imágenes universales, que se han instalado en la imaginación colectiva, hasta el punto de convertirse en estereotipos, imágenes inducidas, creadas por las técnicas de comunicación, que intentan asociar de forma explícita un territorio con una imagen específica y las imágenes accidentales o efímeras, que están ligadas a acontecimientos particulares.

Los análisis de contenido precisan disponer, por su propia naturaleza, de una clasificación de las imágenes que analizan. Sin embargo no existe una categorización homogénea que facilite la estandarización del proceso (Picazo y Moreno-Gil, 2017), incluso hay autores que consideran clasificaciones diseñadas originalmente para medir la imagen percibida del destino, como la desarrollada por Echtner y Ritchie (1993).

Así mismo, cada autor toma en cuenta distintos elementos publicitarios que dan soporte a la visión de los lugares a los cuales se desplazan los turistas. Aunque los más utilizados sean los folletos turísticos (Buck, 1977; Thurot \& Thurot, 1983; Dann, 1988; Pritchard \& Morgan, 1996), también son utilizadas las guías turísticas (Galí \& Donaire, 2005), las postales (Albers, P. \& James, W, 1988; Marwick, 2001; 
Garrod, 2009), los carteles (Hernández, 2008; Descamps y Camprubí, 2018) y las páginas web (Govers \& Go, 2004; Choi, Lehto \& Morrison, 2007). Algunos investigadores hacen uso de más de un medio, normalmente folletos y guías turísticas (Nelson, 2005; Hunter, 2008; Paül, 2018); otros (Mercille, 2005) combinan imágenes inducidas, como las procedentes de guías turísticas, con otras de tipo orgánico (películas y revistas).

Finalmente, existen dos aproximaciones metodológicas al fenómeno de la imagen proyectada. La más frecuente es estática y en ella se estudia en un momento temporal concreto uno (Dann, 1988; Markwell, 1997), o varios destinos (Pritchard \& Morgan, 2001; Echtner, 2002). La perspectiva diacrónica (Markwick, 2001; Galí y Donaire, 2005; Hernández, 2008), examina la evolución de la imagen turística a lo largo del tiempo.

Esta línea de trabajo suele apoyarse en la división del turismo en tres etapas, enraizada en los trabajos de Harvey (1989) y Urry (1990b): el período artesanal (1900-1950), en el cual el moderno turismo de masas surge y va adquiriendo los rasgos que lo caracterizan, la etapa fordista (1951-1974), en la cual el turismo se estandariza de la mano del sistema de viajes organizados en avión para grupos y el desarrollo de una oferta hotelera de tipo industrial, y el turismo postmoderno (1975-2018), en el cual se produce una fragmentación del paquete turístico, la aparición de nuevos agentes aéreos (vuelos low-cost) y una ampliación del tipo de establecimientos (apartamentos, chalets y casas convencionales), de modo que los destinos se segmentan y los motivos de viaje se diversifican.

\section{Metodología}

Los materiales que recogen la imagen proyectada de un destino incluyen un amplio conjunto de representaciones, lo cual determina que el investigador deba tomar una serie de decisiones para acotar su campo de estudio. En primer lugar, tanto la publicidad como las guías van acompañadas de texto. Pese a que no se puede negar su valor para clarificar o enriquecer la información que aportan las imágenes, al analizar tres medios diferentes (carteles, folletos y guías) se podía originar un problema de heterogeneidad en el tipo de información transmitido que ha aconsejado prescindir de éste, centrándonos, como la mayoría de los trabajos, en las fotografías.

En un segundo término, existen elementos de gran visibilidad, (carteles y portadas de folletos y guías turísticas) que el visitante observa sin ningún esfuerzo cuando transita por calles, aeropuertos, centros de información y otros espacios del destino. Junto con ellos, los folletos y las guías incluyen imágenes complementarias: las fotografías interiores, que exigen algún esfuerzo de atención, así como las postales. En estos casos existe una multitud de imágenes y, por ello, presentan una mayor variedad de perspectivas, pero exigen del visitante un proceso de atención. Por este motivo, se ha descartado trabajar con los materiales de baja visibilidad y se utilizan exclusivamente los más perceptibles. Dada su heterogeneidad, no se han tenido en cuenta sus dimensiones, puesto que tampoco es evidente que el hecho de que un cartel sea mayor que una guía o un folleto implique un mayor impacto visual, porque el número de estos últimos es muy superior.

En tercer lugar, según el tipo de agente que los produce, nos encontramos con elementos públicos y privados y, entre estos últimos los establecimientos particulares y las asociaciones, tanto las de promoción turística como las patronales y agencias de viaje. Todos editan materiales publicitarios y, excepto los establecimientos privados (alojamientos, restaurantes, oferta cultural, deportiva y de ocio) ofrecen una visión general del destino, lo cual no quiere decir que sea unívoca, porque cada uno tiene una diferente perspectiva, que además va variando con el paso del tiempo. Por otro lado, las guías turísticas son claramente privadas y proporcionan una perspectiva alternativa del destino, también de tipo general. En principio, esta ha de estar en concordancia con las expectativas de los turistas, pues en ello les va la supervivencia.

Dado que se pretende analizar la evolución de la imagen turística global de un destino, se ha optado por prescindir de los materiales privados de tipo particular, por la dificultad de recoger una muestra significativa durante un siglo, y los problemas de agregación que podía comportar. Para afinar en el sentido que tienen las ilustraciones se utilizan dos tipos de fuentes: por una parte los carteles y los folletos, de naturaleza esencialmente pública, y que son complementarios, ya que se coordinan para mostrar la imagen que se desea proyectar del destino; por otra las guías turísticas. Al evaluar las diferencias y semejanzas entre ambas fuentes constataremos hasta qué punto captan las variaciones en los hábitos de los consumidores 


\section{Tabla 1: Decisiones metodológicas: tipo de materiales a estudiar}

- Imagen: Sí

- Texto: No

- Imagen en exterior: Sí: Folletos, guías turísticas

- Imagen en interior: No

- Imagen pública: Sí: Carteles y folletos

- Imagen privada: - Guías turísticas: Sí

- Publicidad: Asociaciones

El estudio se ha realizado atendiendo tanto al contenido como a la significación de las imágenes. En cuanto al primero, después de analizar las principales opciones disponibles en la literatura, teniendo en cuenta que nos enfrentamos a un destino de costa y no a un destino urbano, se ha optado por una distribución en cuatro categorías:

- poblaciones, que sería forzado considerar como conjuntos monumentales. La mayor parte son núcleos marítimos, frecuentemente adornados por embarcaciones de todo tipo, y por tanto remiten a la idea de la convivencia del hombre con el mar,

- naturaleza o paisaje: la imagen no tiene signos evidentes de la intervención humana. Su argumento fundamental es la costa y las playas,

- patrimonio: la intervención humana se materializa en monumentos u otros elementos de tipo artístico o etnológico, incluidos los de tipo inmaterial, como la gastronomía o los acontecimientos festivos,

- servicios turísticos: actividades culturales, deportivas, o de entretenimiento y establecimientos turísticos.

Tabla 2: Descripción de las categorías que recogen la imagen proyectada

\begin{tabular}{|l|l|}
\hline \multicolumn{1}{|c|}{ Categoría } & \multicolumn{1}{c|}{ Elementos descriptivos } \\
\hline 1. Poblaciones & Población marinera: junto al mar o dotada de puerto \\
\hline & Población blanca: (casi) todos los edificios son blancos \\
\hline 2. Paisaje natural & Playa virgen \\
\hline & Aguas marinas sin embarcaciones \\
\hline & Costa rocosa sin embarcaciones \\
\hline & Cala con barcas \\
\hline & Costa rocosa con embarcaciones \\
\hline 3. Patrimonio & Playa urbanizada o con bañistas \\
\hline & Monumentos arqueológicos \\
\hline & Elementos etnológicos blancos: casa rural, tejado,... \\
\hline & Bienes del patrimonio material: iglesias, palacios,... \\
\hline 4. Servicios turísticos & Patrimonio inmaterial: gastronomía, fiestas y otros \\
\hline & Actividades culturales, deportivas o de entretenimiento \\
\hline & Hoteles y otros alojamientos turísticos \\
\hline
\end{tabular}

En la mayoría de los casos, los elementos portadores de imagen incluyen una única fotografía, pero, en algunos pocos, aparecen varias. En estas situaciones, se han propuesto diversas alternativas: desde contar cada imagen de forma independiente (Pritchard y Morgan, 1996) a considerar únicamente los "eye-catchers": las ilustraciones que ocupan más del 50\% del espacio (Pritchard y 
Morgan, 1995). En nuestro caso, al tratarse de una problemática muy reducida, se ha optado por contabilizar la porción de espacio ocupada por cada representación y atribuir a cada imagen el tanto por uno que supone, de manera que la suma de todas es uno. Así se evita tanto sobrerrepresentar algunas fotografías como eliminar el efecto de estas. En el caso de los folletos, se ha tenido en cuenta la portada y la contraportada, los cuales, además, no siempre son fáciles de distinguir a primera vista.

El tipo de clasificación propuesta ha simplificado la tarea de asignar las imágenes a cada categoría, al tratarse de elementos bien diferenciados. El único problema suscitado fueron las actividades marítimas, las cuales se suelen desarrollar en un entorno que puede ser natural o humanizado. Después de la oportuna discusión, se optó por asignarlas a la categoría predominante que, en casi todos los casos resultó ser el paisaje natural o la población, ya que sólo en un número muy reducido de ocasiones la actividad de ocio marítimo tenía relevancia y la imagen se incluyó en la categoría de "servicios turísticos".

La muestra objeto de estudio está compuesta por 161 elementos, la mayor parte de los cuales son guías de viaje (67), seguidos de los folletos (56) y, por último los carteles (38). Se trata de la práctica totalidad del material publicitario de esta clase editado entre 1911 y 2006. Para analizar la evolución de la imagen de la isla, se consideran los tres períodos más asentados en la bibliografía sobre la historia del turismo: artesanal (1900-1950), fordista (1951-1974) y postmoderno (1975-2006).

Tabla 3: Material turístico objeto de estudio

\begin{tabular}{|l|r|r|r|r|}
\hline \multicolumn{1}{|c|}{ Periodo } & \multicolumn{1}{c|}{ Guías } & Folletos & Carteles & \multicolumn{1}{c|}{ Suma } \\
\hline $1911-1950$ & 4 & 3 & 2 & 9 \\
\hline $1951-1974$ & 9 & 25 & 5 & 39 \\
\hline $1975-2006$ & 54 & 28 & 31 & 113 \\
\hline $1975-1992$ & 24 & 10 & 20 & 54 \\
\hline $1993-2006$ & 30 & 18 & 11 & 59 \\
\hline Suma & $\mathbf{6 7}$ & $\mathbf{5 6}$ & $\mathbf{3 8}$ & $\mathbf{1 6 1}$ \\
\hline
\end{tabular}

Como se observa en la tabla, la progresión de los elementos portadores de imagen es continua: en el período fordista se multiplican por tres y en la fase más moderna, casi se triplican. Esta sobreabundancia final, en ocasiones exigirá efectuar una subdivisión, siendo un momento lógico de separación el año 1993, en que la isla fue declarada por la UNESCO reserva de biosfera. El número de carteles y folletos editados por las entidades públicas (Estado central, Comunidad Autónoma y Consejo Insular) es el mismo que el de las organizaciones de tipo privado, entre las que destaca, por su antigüedad y amplitud del material producido, el Fomento del Turismo de Menorca.

Tabla 4: Agentes turísticos que editan carteles y folletos

\begin{tabular}{|l|r|r|r|r|}
\hline Periodo & \multicolumn{1}{|c|}{$\mathbf{1 9 1 1 - 1 9 5 0}$} & $\mathbf{1 9 5 1 - 1 9 7 4}$ & $\mathbf{1 9 7 5 - 2 0 0 6}$ & \multicolumn{1}{c|}{ Suma } \\
\hline Estado central & & 5 & 7 & 12 \\
\hline Comunidad Autónoma & & & 24 & 24 \\
\hline Consejo Insular & & & 11 & 11 \\
\hline Fomento del Turismo de Menorca & 5 & 25 & 13 & 43 \\
\hline Asociaciones patronales y agencias & & & 4 & 4 \\
\hline Fomento del Turismo de Menorca & $\mathbf{5}$ & $\mathbf{3 0}$ & $\mathbf{5 9}$ & $\mathbf{9 4}$ \\
\hline
\end{tabular}




\section{Resultados}

\subsection{El contenido de la imagen proyectada de Menorca}

En el momento de empezar a desarrollar la imagen de la isla, con el objetivo de cautivar a los potenciales visitantes, los agentes turísticos no partían de cero. La introducción de la primera guía, editada en 1911, se propone ofrecer noticias claras y precisas a "el viajero sin más objetivo que el mismo viaje, el turista". Para ello tenían la experiencia tanto de las personas que a lo largo el siglo XIX habían ido recalando en Menorca como de las descripciones que ofrecían libros de viaje, guías turísticas y reportajes periodísticos, que ya habían decantado una imagen literaria del lugar (Méndez, 2017). El reto era transferir ésta al material gráfico, que de cada vez más será el soporte preferido.

Los principales atractivos que destaca esta literatura son las poblaciones, especialmente Mahón, asomándose al puerto al que da nombre, pero también Ciudadela. Como segundo punto de atracción se sitúan los monumentos prehistóricos. Los paisajes del interior aparecen más raramente y la costa sólo emergerá a partir del 1920. Para la mayoría de los visitantes, Menorca era blanca y limpia. El título de una obra, "Menorca, la isla blanca-azul" (Davins, 1925), sería el origen del eslogan turístico que, bendecido por el Ministerio de Información y Turismo, perdurará todo el siglo XX. Sin embargo, también se destacaba un paisaje pedregoso poco atractivo; un clima riguroso, así como la ausencia de exotismo. Un escritor lo definía con los adjetivos "piedras y viento" (Verdaguer, 1928).

Este punto de partida está muy presente en la etapa artesanal del turismo de la isla: los paisajes tienen un papel marginal y la imagen se concentra en las poblaciones y los elementos del patrimonio cultural y etnológico, con una leve preponderancia de los primeros. Con el paso al turismo fordista la situación da un vuelco y la naturaleza pasa a ser el primer argumento en el imaginario de la isla. El tránsito a los tiempos postmodernos alterará poco esta concepción, únicamente se reduce levemente el peso de las poblaciones en favor de los factores de tipo cultural. En ambos casos, los servicios turísticos son un aspecto que trasciende poco en la promoción turística.

Tabla 5: Clasificación de las imágenes de Menorca (\% sobre el total de materiales)

\begin{tabular}{|l|l|l|l|l|}
\hline \multicolumn{1}{|c|}{ Periodo } & $\mathbf{1}$ & $\mathbf{2}$ & $\mathbf{3}$ & \multicolumn{1}{c|}{} \\
\hline $1911-1950$ & $44,4 \%$ & $16,7 \%$ & $38,9 \%$ & $0,0 \%$ \\
\hline $1951-1974$ & $32,7 \%$ & $41,7 \%$ & $20,5 \%$ & $5,1 \%$ \\
\hline $1975-2006$ & $27,3 \%$ & $43,7 \%$ & $28,1 \%$ & $0,9 \%$ \\
\hline Total & $\mathbf{2 9 , 5} \%$ & $\mathbf{4 1 , 7 \%}$ & $\mathbf{2 6 , 9} \%$ & $\mathbf{1 , 9} \%$ \\
\hline
\end{tabular}

1: Poblaciones; 2: Paisajes; 3: Patrimonio; 4: Serv. turíst.

No obstante, si examinamos por separado los carteles y folletos, por una parte y las guías turísticas, por otro, apreciamos sensibles diferencias. En general la publicidad oficial ha estado más interesada en presentar Menorca como un entorno natural (48,9\%) que las guías de viaje (31,6\%). En aquélla, los elementos patrimoniales tienen un peso superior a las poblaciones, más valorados en las guías.

Tabla 6: Imágenes de Menorca según el soporte (carteles y folletos vs. guías turísticas)

\begin{tabular}{|l|c|c|c|c|c|c|c|c|}
\hline & \multicolumn{2}{|c|}{ 1. Poblaciones } & \multicolumn{2}{c|}{ 2. Paisajes } & \multicolumn{2}{c|}{ 3. Patrimonio } & \multicolumn{2}{c|}{ 4. Serv. turísticos } \\
\hline Periodo & cartel-foll. & guía tur. & cartel-foll. & guía tur. & cartel-foll. & guía tur. & cartel-foll. & guía tur. \\
\hline $1911-1950$ & $20,0 \%$ & $75,0 \%$ & $30,0 \%$ & $0,0 \%$ & $50,0 \%$ & $25,0 \%$ & $0,0 \%$ & $0,0 \%$ \\
\hline $1951-1974$ & $25,8 \%$ & $55,6 \%$ & $45,8 \%$ & $27,8 \%$ & $21,7 \%$ & $16,7 \%$ & $6,7 \%$ & $0,0 \%$ \\
\hline $1975-2006$ & $22,9 \%$ & $32,1 \%$ & $52,1 \%$ & $34,5 \%$ & $23,3 \%$ & $33,4 \%$ & $1,7 \%$ & $0,0 \%$ \\
\hline $1975-1992$ & $25,3 \%$ & $43,2 \%$ & $50,2 \%$ & $23,8 \%$ & $24,5 \%$ & $33,0 \%$ & $0,0 \%$ & $0,0 \%$ \\
\hline $1993-2006$ & $20,3 \%$ & $23,2 \%$ & $57,6 \%$ & $43,2 \%$ & $22,1 \%$ & $33,7 \%$ & $0,0 \%$ & $0,0 \%$ \\
\hline Total & $\mathbf{2 3 , 7 \%}$ & $\mathbf{3 7 , 8} \%$ & $\mathbf{4 8 , 9} \%$ & $\mathbf{3 1 , 6} \%$ & $\mathbf{2 4 , 2} \%$ & $\mathbf{3 0 , 6} \%$ & $\mathbf{3 , 2} \%$ & $\mathbf{0 , 0} \%$ \\
\hline
\end{tabular}


Esta diferenciación ya aparece en el periodo artesanal, en el que carteles y folletos empiezan a hacerse eco de los paisajes y presentan como gran argumento los bienes patrimoniales, mientras las guías se decantan claramente por las poblaciones. La naturaleza no será hegemónica en éstas, como sí en la publicidad oficial, aunque la tendencia será que las guías vayan asumiendo el discurso oficial. Las guías dan la espalda a los servicios turísticos.

\section{Gráfico 1: Imagen principal según el soporte}

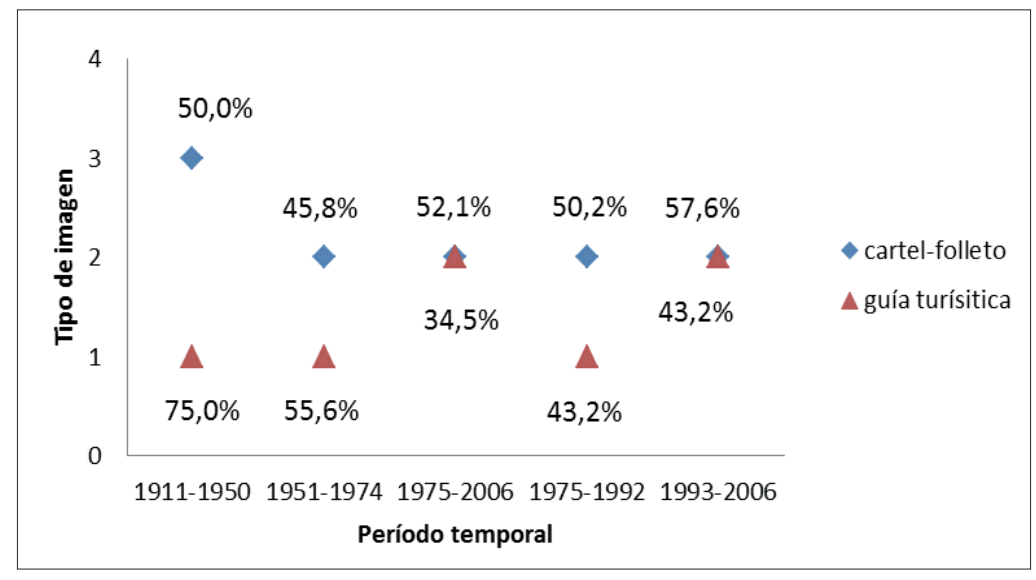

La convergencia es mayor de lo que los grandes períodos permiten apreciar. Con la declaración de Menorca por la UNESCO como reserva de biosfera, en 1993, se reforzó su imagen como paraíso natural. Si analizamos lo que ha ocurrido en estos dos subperíodos, constatamos como la imagen transmitida por carteles y folletos ve un aumento constante del peso de los paisajes. En las guías, por su parte, los paisajes perdieron importancia entre 1975 y 1992, pero los años siguientes se han acercado bastante a la publicidad institucional y la naturaleza por primera vez es el principal argumento icónico en detrimento de las poblaciones. Este hecho nos debería poner alerta sobre los cambios producidos en lo que se ha denominado postmodernidad, pues lejos de ser una etapa uniforme, dentro de ella se producen cambios relevantes en la imagen proyectada, en este caso el aumento del peso de la naturaleza, que hacen difícil sostener que sean una etapa unitaria.

\subsection{Los significados de la imagen de Menorca}

La clasificación del contenido oculta diferentes realidades, el análisis de cuyo significado nos permite perfilar las grandes líneas que acabamos de trazar sobre la evolución de la imagen turística de Menorca, pues cada una de las representaciones comentadas tiene diferentes expresiones.

La relativa a los núcleos habitados adopta diversas formas. Las poblaciones marineras ofrecen una visión de los puertos de las dos principales ciudades de la isla, Mahón y Ciudadela, en los cuales habitualmente están ancladas o navegan embarcaciones, ya sean de pasaje, pesqueras o de recreo, formando un conjunto integrado que lanza el mensaje de tranquilo lugar al borde del mar. Esta concepción es la que se presenta en la portada de la primera guía de 1911 y su origen se puede rastrear en los cuadros de esta temática, habituales en los pintores locales, cuya inspiración proviene de la tradición pictórica y de forma notable los lienzos sobre Venecia, famosos desde el siglo XVIII gracias a Canaletto (1697-1768), que en el XIX experimentaran una interpretación en clave romántica (Turner, 1775-1851). Como contrapunto, encontramos los núcleos costeros, agrupaciones de humildes casitas construidas para el ocio ligado al mar. La primera escena de este tipo ilustra la guía de 1948, en la cual se puede ver una colonia veraniega del puerto de Mahón. En este caso, más que paralelismos y antecedentes, nos hallamos ante un elemento nuevo que los agentes turísticos juzgan que tiene un potencial atractivo para el visitante, básicamente por su tipismo. A continuación, cabe hablar de los pueblos blancos, que expresan la misma idea de los elementos etnológicos de esta índole. De hecho, algunas imágenes de las otras dos categorías se podrían encuadrar aquí, por lo que reservamos este epígrafe para los que 
no están al borde del mar. Finalmente, el apartado de otros se refiere a las urbanizaciones turísticas y núcleos diferentes de los anteriores, de reducida presencia.

Los carteles y folletos, hasta el final de la etapa fordista reflejaban principalmente los núcleos de costa, pero a partir del 1975 pasan a tener más peso las poblaciones marineras; en cambio las guías reparten su atención entre ambos de forma más equitativa (aunque durante la fase fordista, la presencia de los pueblos blancos es mayor), si bien modernamente también se apoyan en las poblaciones. El desplazamiento de la atención general a las principales ciudades, Mahón y Ciudadela, se debe atribuir al hecho de que estas asuman la función de transmitir las señas de identidad de la isla.

Tabla 7: Imágenes de las poblaciones según el soporte (\% sobre el total de materiales)

\begin{tabular}{|l|c|c|c|c|c|c|c|c|}
\hline & \multicolumn{2}{|c|}{$\begin{array}{c}\text { Población } \\
\text { marinera }\end{array}$} & \multicolumn{2}{|c|}{ Núcleo de costa } & \multicolumn{2}{c|}{ Pueblo blanco } & \multicolumn{2}{c|}{ Otros } \\
\hline Periodo & cartel-foll. & $\begin{array}{c}\text { guía } \\
\text { tur. }\end{array}$ & cartel-foll. & guía tur. & cartel-foll. & guía tur. & cartel-foll. & guía tur. \\
\hline $1911-1950$ & $0,0 \%$ & $50,0 \%$ & $100,0 \%$ & $50,0 \%$ & $0,0 \%$ & $0,0 \%$ & $0,0 \%$ & $0,0 \%$ \\
\hline $1951-1974$ & $28,9 \%$ & $20,0 \%$ & $65,3 \%$ & $20,0 \%$ & $0,0 \%$ & $60,0 \%$ & $5,8 \%$ & $0,0 \%$ \\
\hline $1975-2006$ & $54,8 \%$ & $53,6 \%$ & $34,1 \%$ & $42,4 \%$ & $11,1 \%$ & $3,1 \%$ & $0,0 \%$ & $0,9 \%$ \\
\hline Suma & $\mathbf{4 2 , 8} \%$ & $\mathbf{4 6 , 1} \%$ & $\mathbf{4 8 , 6} \%$ & $\mathbf{3 8 , 3} \%$ & $\mathbf{6 , 5} \%$ & $\mathbf{1 5 , 0} \%$ & $\mathbf{2 , 2} \%$ & $\mathbf{0 , 6} \%$ \\
\hline
\end{tabular}

El entorno natural siempre se ha considerado el elemento diferencial de los destinos de costa. Si nos centramos en las imágenes del litoral, que suponen el $84 \%$ del total, podemos hallar diversas representaciones. Una muy característica de Menorca es la costa rocosa, escarpada o no, y de forma frecuente poblada de pinos o matorrales. El segundo elemento son las calas, similares a las anteriores, pero que cuentan con un pequeño arenal. Lógicamente también se hallan las playas sin (apenas) urbanizar. En último extremo, se encuentran las fotografías de aguas, sin ningún complemento más que alguna barca, y las playas al pie de núcleos turísticos.

\section{Gráfico: Imágenes del litoral según el soporte}

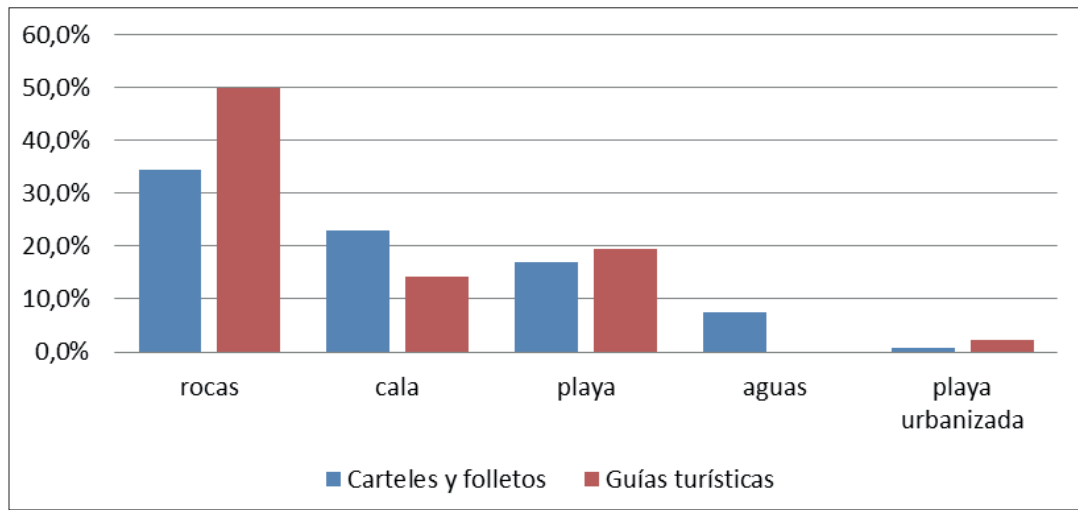

En la etapa artesanal únicamente se muestra esta iconografía en los carteles y folletos, donde las playas son mayoritarias. Durante la etapa fordista, el litoral rocoso asume un importante papel, muy parecido en todos los soportes. Sin embargo, los carteles y folletos ofrecerán de forma mayoritaria la visión de las calas, normalmente con una ladera poblada de pinos, una escenografía ausente de las guías, que prefieren las playas y no rehúyen las playas urbanizadas, aunque con una presencia minoritaria. 
Tabla 8: Principales imágenes del litoral según el soporte (\% de paisajes)

\begin{tabular}{|l|c|c|c|c|c|c|}
\hline & \multicolumn{2}{|c|}{ Rocas } & \multicolumn{2}{c|}{ Cala } & \multicolumn{2}{c|}{ Platja } \\
\hline Periodo & cartel-foll. & guía tur. & cartel-foll. & guía tur. & cartel-foll. & guía tur. \\
\hline $1911-1950$ & $0,0 \%$ & $0,0 \%$ & $0,0 \%$ & $0,0 \%$ & $66,7 \%$ & $0,0 \%$ \\
\hline $1951-1974$ & $40,7 \%$ & $40,0 \%$ & $54,2 \%$ & $0,0 \%$ & $0,0 \%$ & $40,0 \%$ \\
\hline $1975-2006$ & $33,1 \%$ & $51,2 \%$ & $9,4 \%$ & $16,1 \%$ & $22,7 \%$ & $16,6 \%$ \\
\hline Suma & $\mathbf{3 4 , 4 \%}$ & $\mathbf{4 9 , 9 \%}$ & $\mathbf{2 2 , 9} \%$ & $\mathbf{1 4 , 2} \%$ & $\mathbf{1 7 , 1 \%}$ & $\mathbf{1 9 , 4 \%}$ \\
\hline
\end{tabular}

Por último, en la etapa actual, la costa rocosa se consolida como el primer emblema de la isla, especialmente en las guías turísticas; en segundo lugar se presentan las playas, quedando en tercer término las calas. De hecho, el desarrollo de la imagen turística tiende a privilegiar las playas, que ganan peso a partir del 1993. En las calas, las laderas de rocas y los arbustos substituyen a los pinares del período anterior.

Cada uno de estos elementos es susceptible de diversas lecturas. Las playas en la etapa fordista aparecen siempre rodeadas de un pinar, que casi no deja ver la arena ni el agua. Esta escenografía será sustituida paulatinamente por laderas rocosas pobladas con matorrales y algunos árboles. Finalmente, a partir del 1993, la arena y el agua, que hasta entonces raramente eran las protagonistas, acaban siendo el principal argumento visual.

La iconografía costera no se puede reducir a sus elementos terrestres, ya que el otro factor del binomio, el mar, tiene una importancia considerable y, además, la parte de la fotografía que ocupa va en aumento. Las aguas tienen diversas facetas. El color puede ser sólido, de un azul intenso, o de un suave azul turquesa, o adquirir diversos matices de azul y verde. También puede crear un bello efecto de espejo que refleja árboles o barcas. No obstante, la transparencia será el valor dominante. En la etapa fordista surge la escena de una embarcación que flota sobre unas aguas tan límpidas que proyecta su sombra al fondo, la cual será repetida en innumerables ocasiones, tanto en playas arenosas como en blancos acantilados calizos, una manera ingeniosa de unir los aspectos marinos y solares del litoral.

Los diferentes tipos de imágenes no tienen el mismo significado. Las playas nos remiten a la clásica idea de paraíso, entendido como un lugar apropiado para el relax, el disfrute placentero del sol y el mar. Las rocas costeras, en ocasiones formando acantilados escarpados, en cambio, se deben vincular al concepto romántico de "lo sublime", una naturaleza salvaje que constituye un espectáculo digno de ser contemplado.

Esta codificación se consigue mediante la repetición de los lugares que se pueden ver en las representaciones gráficas, que se concentran en muy pocos lugares del amplio litoral de la isla, aproximadamente una docena. Estos espacios son fotografiados desde diferentes puntos de vista (desde tierra, desde el mar, desde el aire, del este, el oeste,...), pero al ser básicamente los mismos, permiten estandarizar la imagen transmitida en la búsqueda de los arquetipos universales a los que nos acabamos de referir.

Aunque estas iconografías no experimentan excesivos cambios a lo largo de casi un siglo, sí lo hace el punto de vista del observador. Esto se consigue gracias a la identificación universal de éste con los personajes o elementos de la imagen: un espacio vacío nos hace pensar en el disfrute solitario del paraje; si en éste figura una barca, nos vemos navegando en ella. Por el contrario, una playa en la cual hay un grupo de personas en la arena, o de barcas en el mar, transmite la idea de lugar compartido. De este modo, cada grupo de imágenes tiene sus asociaciones preferidas: la playa y la cala están vacías en la mitad de las ilustraciones, mientras que junto a las rocas navega una embarcación (casi siempre un yate) en dos terceras partes de éstas. Está claro que las playas son para el disfrute tranquilo del mar y el sol y los precipicios y paisajes rocosos, para recorrerlos en una barca.

Estas representaciones no son estáticas y tienden a acompasarse con la evolución del turismo, cada vez más masificado. Si, en las etapas artesanal y fordista, la única fotografía es de una playa solitaria, entre 1975 y 1992 esta estampa reduce su frecuencia relativa a la mitad y desde 1993 a una tercera parte. La costa rocosa, por su parte, surge en la fase fordista, el $57 \%$ de las veces como marco de una embarcación aislada y el $29 \%$ en solitario. A partir de 1975 , estas dos escenas se reducen al $28 \%$ y el $11 \%$, y lo que predomina es un grupito de barcas (36\%) o alguna construcción (14\%). De forma significativa, en un $10 \%$ de las fotografías se puede ver un nutrido conjunto de bañistas. Las calas son un territorio a caballo entre estos dos extremos: en el periodo fordista eran lugares solitarios 
(68\% sin personas y $14 \%$ con un único visitante) o con una barca (18\%). A partir del 1975 el espacio vacío se retrae ( $14 \%$ sin nadie y $14 \%$ con un excursionista) y la barca solitaria (14\%) es sobrepasada por el conjunto de yates (33\%); de hecho en el 17\% el entorno da síntomas, sino de masificación, sí de una frecuentación numerosa.

En cuanto a los elementos de tipo cultural y patrimonial, los dos principales son los monumentos arqueológicos y las casas y otros elementos etnológicos blancos, que suponen el 66,5\% del total. En el periodo artesanal únicamente aparecen las segundas, aunque sólo en los carteles y folletos. Al pasar a la etapa fordista, esta imagen se generaliza y es mayoritaria en ambos soportes, mientras que los monumentos son un factor secundario. Sin embardo, a partir de 1975 la situación se revierte y los monumentos prehistóricos pasan a tener un papel central, si bien las típicas construcciones blancas les siguen de cerca.

Tabla 9: Imágenes patrimoniales (\% sobre patrimoniales de su clase)

\begin{tabular}{|l|c|c|c|c|}
\hline & \multicolumn{2}{|c|}{ Monumentos arqueológicos } & \multicolumn{2}{c|}{ Elementos etnológicos blancos } \\
\hline Periodo & cartel-foll. & guía turística & cartel-foll. & guía turística \\
\hline $1911-1950$ & $0,0 \%$ & $0,0 \%$ & $100,0 \%$ & $0,0 \%$ \\
\hline $1951-1974$ & $15,4 \%$ & $33,3 \%$ & $38,5 \%$ & $66,7 \%$ \\
\hline $1975-2006$ & $36,4 \%$ & $34,4 \%$ & $30,9 \%$ & $32,3 \%$ \\
\hline Suma & $\mathbf{2 6 , 4 \%}$ & $\mathbf{3 2 , 6 \%}$ & $\mathbf{4 0 , 7} \%$ & $\mathbf{3 3 , 3 \%}$ \\
\hline
\end{tabular}

Por tanto, podemos comprobar como la propuesta inicial de los agentes turísticos, identificar Menorca por sus casas blancas de evocación rural, se va matizando con el paso del tiempo y al final, aún manteniendo una presencia no despreciable, deben ceder el protagonismo a los monumentos megalíticos, que progresan de manera continua a lo largo del tiempo.

Finalmente, conviene hacer una revisión del turismo náutico, la actividad de ocio más presente en la iconografía isleña. Como contrapunto, aparecen las embarcaciones marineras, sean barcas de pesca o buques de marina mercante, los cuales son un recordatorio o símbolo del carácter marítimo de poblaciones y lugares de la costa.

Tabla 10: Imágenes marineras (\% sobre población y naturaleza)

\begin{tabular}{|l|c|c|c|c|}
\hline & \multicolumn{2}{|c|}{ Turismo náutico } & \multicolumn{2}{c|}{ Embarcaciones marineras } \\
\hline Periodo & cartel-foll. & guía turística & cartel-foll. & guía turística \\
\hline $1911-1950$ & $40,0 \%$ & $33,3 \%$ & $0,0 \%$ & $66,7 \%$ \\
\hline $1951-1974$ & $41,1 \%$ & $26,7 \%$ & $12,8 \%$ & $26,7 \%$ \\
\hline $1975-2006$ & $34,3 \%$ & $11,1 \%$ & $27,0 \%$ & $38,1 \%$ \\
\hline Suma & $\mathbf{3 6 , 7 \%}$ & $\mathbf{1 5 , 1 \%}$ & $\mathbf{2 1 , 3} \%$ & $\mathbf{3 8 , 1 \%}$ \\
\hline
\end{tabular}

Como se puede apreciar, el peso del turismo náutico en las imágenes en las que se puede ver (poblaciones y naturaleza) es decreciente, mientras que los elementos marineros, que no se asocian a ningún tipo de actividad, aumentan de manera constante. Los carteles y folletos siempre se decantan por el turismo náutico. De hecho, en los carteles del Estado central es omnipresente y frecuente en los folletos; la Comunidad Autónoma, la administración local y las entidades privadas no le prestan tanta atención. Las barcas y buques anclados junto a muelles son la apuesta central de las guías turísticas y, aunque en la etapa fordista compartirán protagonismo con el turismo náutico, a partir del 1975 vuelve a estar claro que la asociación más general y simbólica predomina sobre las actividades más específicamente náuticas. 


\section{Conclusiones}

Este artículo se centra en la conceptualización de la imagen proyectada por los destinos de costa a partir del análisis de un lugar, Menorca, que se considera representativo de este tipo de destinos turísticos. La metodología utilizada se basa en utilizar un amplio espectro de materiales turísticos (carteles, folletos y guías) y analizar su progreso durante el lapso de un siglo. Ninguno de estos enfoques -destinos costeros, diversidad de soportes y proceso histórico- son abundantes en la bibliografía sobre la imagen proyectada. Su relevancia estriba, precisamente, en el avance ofrecido sobre la imagen de los destinos costeros, los cuales, pese a la considerable importancia de sus flujos turísticos, no cuentan con demasiados estudios.

Los resultados demuestran que la imagen proyectada por los destinos de costa presenta unas particularidades que los distinguen de la que poseen países, regiones y ciudades, herederos de la visión romántica de su historia y tradiciones, representada a través de sus monumentos y poblaciones. Sin embargo, no se trata que estos se hallen ausentes de los destinos de costa ni que se ofrezca únicamente fotografías de las playas. Al contrario, se trata de una iconografía bastante variada, donde conviven diversos elementos.

Los destinos del litoral son un concepto relativamente moderno que han tenido que construirse una imagen, y quizá por ello, a diferencia de los urbanos y regionales, han experimentado una evolución considerable (Galí y Donaire, 2005; Hernández, 2008), de manera que la visión que mostraban al principio -poblaciones ligadas al mar- difiere netamente de lo que se acabará entendiendo por un destino de costa. Será en la etapa fordista cuando se forje la escenografía costera que, con el paso del tiempo, lejos de matizarse, incluso se ha fortalecido.

Los agentes turísticos ofrecen un paquete complejo, que tiene como principal protagonista al mar, el cual exhibe un doble aspecto: por un lado, como lugar de reposo, contemplación y espacio para actividades náuticas y, por otro, sus poblaciones marineras son el marco de tranquilos paseos y vistas pintorescas. Los ingredientes culturales y patrimoniales que denotan la presencia humana no están ausentes de este coctel, sino que las construcciones típicas y los aspectos monumentales tienen un peso creciente.

Incluso este trazado es excesivamente esquemático, ya que no existe una iconografía única de ninguno de los tres contenidos principales. La costa no es sinónimo de playa, sino que coexiste con las calas y los roquedos costeños. Ambas tienen funciones bien diversas, la primera, asociadas al ocio y a la evocación del paraíso soñado por los turistas, mientras que las rocas litorales se vinculan a la idea romántica de la naturaleza imponente, aunque modernizada, puesto que se propone su disfrute con una embarcación, tradicional o, más habitualmente, un yate. La playa admite diversas interpretaciones: ligada al paisaje terrestre que la rodea sugiere una agradable excursión campestre, pero orientada al mar y el sol remite al codiciado arenal caribeño. A pesar de la tendencia a la diversificación de la demanda, la playa de arena, lejos de ser un fenómeno de la etapa fordista, recientemente gana importancia y adquiere un relieve que antes no tenía, lo que nos alerta sobre los movimientos de fondo de la demanda turística. Asimismo, pese a que los espacios costeros tienen una fuerte querencia por el disfrute solitario, su imagen no es inmune a la masificación y en su iconografía se constata un aumento de la presencia humana. De este modo, la imagen turística del litoral se nos aparece como un mosaico, un concepto multidimensional, alejado de un producto turístico simple -sol y playa- que, además, va reacomodándose a medida que varían las expectativas de los turistas.

En este trabajo también se realizan aportaciones de tipo teórico. En primer lugar, se plantea la necesidad de reconsiderar la unidad de fase postmoderna o postfordista de la historia del turismo, pues la acumulación de cambios producidos desde 1975 conlleva que los turistas del siglo XXI y el producto ofrecido por los destinos costeros tengan poco que ver con los de la segunda mitad de los setenta, lo cual implica una alteración en la imagen proyectada (y presumiblemente, percibida). Postular la continuidad de esta etapa puede oscurecer las transformaciones acaecidas, por lo cual su subdivisión contribuye a un mejor conocimiento. En nuestro caso, 1993 es un buen vierteaguas, sea por un acontecimiento local (declaración de reserva de biosfera) o por responder a algún desarrollo turístico global.

En segundo lugar se comprueba cómo, según ya habían apuntado estudios anteriores (Hunter, 2016; Paül, 2018), los soportes elegidos no son neutrales. Las fuentes públicas -carteles y folletoshistóricamente han mostrado una escenografía diferente de las guías turísticas, aunque existe una tendencia a la convergencia entre ambas. En este sentido, la orientación al mercado de las guías permite postular que la imagen que ofrecen se aproxime más a la imagen percibida por el consumidor. Por este motivo es revelador que, en general, las guías hayan ido adaptado su iconografía a los carteles y los folletos. Es posible que esto se deba al éxito de las modernas técnicas de comunicación en adoptar unos arquetipos universales aceptados por los turistas. Mediante la reiteración de los lugares representados, 
se codifica una imagen turística que se instala en la imaginación colectiva. De hecho, la mayoría de destinos turísticos cuentan con lo que se ha venido en llamar "lugares emblemáticos", donde se genera una gran acumulación de visitas, como la Fontana de Trevi en Roma, la Sagrada Familia en Barcelona o la cala de Macarella en Menorca.

Por otra parte, las guías turísticas, que en principio deberían estar más próximas a los turistas, son los soportes más reacios a mostrar la costa y los que intenten reflejar un aspecto más plural del destino turístico, donde lo más notorio son las poblaciones costeras, especialmente los núcleos urbanos, adornados con embarcaciones marineras. En cambio, la publicidad oficial potencia la idea de paisaje costero, con un fuerte impulso del turismo náutico.

En definitiva, es necesario apuntar las complejas relaciones entre la imagen percibida por el turista y la que proyecta el destino. Estas dos esferas no son independientes, puesto que al crear una imagen siempre se deben tener en cuenta las expectativas de los visitantes, lo cual es un mecanismo que refuerza "el círculo hermenéutico o de representaciones", a través del cual se tiende a perpetuar la imagen de un destino (Urry, 1990b; Jenkins, 2003). El turismo es una industria experimental, donde la dinámica de prueba y error produce un alineamiento entre la imagen percibida y la imagen proyectada. Sin la aceptación activa de los clientes, estos elementos perderían su atractivo y dejarían de utilizarse. Esto no excluye, por supuesto, que la imagen turística no sea una representación artificial que puede alejarse de la realidad social, puesto que el proceso retroalimentado se suele cerrar alrededor de un conjunto de elementos que los visitantes gustan de ver y los operadores turísticos pueden ofrecer, creando un espacio ficticio de "autenticidad compartida".

Con el tiempo, incluso es posible que ciertos ámbitos de representación acaben adoptando rasgos reales. En Menorca el caso más paradigmático es el poblado de pescadores de Binibeca, un pequeño núcleo residencial diseñado ex novo a finales de los sesenta para imitar un conjunto marinero tradicional, que en su momento fue publicitado como la quintaesencia de la isla y se ha consolidado como una atracción turística y un auténtico lugar de veraneo que a fuerza de ser parcialmente imitado ha adquirido un aire de realidad, pues tiene puntos en común con otras urbanizaciones de la costa.

Estos resultados ofrecen pautas para los responsables de gestionar la imagen de los destinos costeros. En primer lugar, deberían ser conscientes de la amplitud del producto turístico y de la atención que prestan los visitantes al entorno urbano y a los elementos patrimoniales e intangibles, e integrarlos en sus esfuerzos de marketing. Asimismo, sería útil diversificar la imagen transmitida y no centrarse en demasía en los elementos icónicos que, además de los problemas de gestión que produce la afluencia excesiva de turistas, ensombrecen otros que los turistas también incorporan en su imagen percibida del destino (Paül, 2018). Finalmente, es conveniente que los agentes turísticos estén atentos a la variación de los gustos y tendencias de los consumidores a lo largo del tiempo, puesto que estos van evolucionando y exigen una puesta al día de la imagen proyectada si no se quiere defraudar sus expectativas.

A pesar de todo, se deberían señalar una serie de limitaciones del presente estudio. En primer lugar, no se ha analizado explícitamente la imagen percibida por los turistas. Futuras investigaciones pueden considerar este aspecto de la imagen turística en la actualidad. En particular, sería muy interesante que se verifique si la imagen proyectada por las guías turísticas se aproxima más a la imagen percibida que la de los carteles y folletos. Por otra parte, pese a que no es sencillo recoger esta desde un punto de vista histórico, una alternativa sería tener en cuenta las descripciones de libros de viaje, artículos periodísticos u otras fuentes susceptibles de acercarse a la percepción del turista.

En segunda instancia, este trabajo no ha utilizado las posibilidades que ofrecen las redes sociales y otros medios telemáticos de transmisión de información. Actualmente, los destinos son cada vez más activos en ofrecer un perfil digital que proyecte su imagen turística, por lo cual los resultados del último período de estudio podrían ser matizados. Mayor importancia tienen, si cabe, si se desea conocer la imagen percibida por los turistas.

En tercer lugar, el análisis de las imágenes se ha realizado mediante un proceso observacional basado en la experiencia del investigador. Un posible refinamiento sería la utilización de un programa de análisis cualitativo asistido por ordenador (CAQDAS). Pese a que la mayoría de estas herramientas se fundamenta en el rastreo de textos, existen algunas aplicaciones capaces de considerar imágenes (ATLAS, MAXQDA). Un avance adicional sería, precisamente, la inclusión de los textos que acompañan a las imágenes, lo cual exigiría un trabajo previo de estandarización de los diferentes materiales.

Para finalizar, futuras investigaciones podrían extender este estudio a otras localidades de costa para verificar si las conclusiones obtenidas tienen la generalidad que se les ha supuesto. De este modo también se podría comprobar si es necesario subdividir el período postmoderno y si existe una periodificación de alcance global o esta depende de los tipos de destino, áreas geográficas o episodios locales. 


\section{Bibliografía}

Albers, P., James, W. 1988. Travel Photography: A Methodological Approach. Annals of Tourism Research, $15,134-158$

Alonso, 1. 2010. El turismo de salud en España, 1750-2009. En Anuario del CEEED, 2, 11-49.

Anjos, F.A. y Pereira, M.L. (2017). Evaluation of the image of a coastal tourism destination in Brazil. International Journal of Tourism Cities, 3, 324-338.

Ashworth, G.J. 1991. Products, places and promotion: destination images in the analysis of tourist industry. En Sinclair, M., Stabler, M. (ed.) The tourist industry: An international analysis. Wallingford: Cab International, 121-142.

Baloglu, S., Brinberg, D. 1997. Affective images of tourism destination. Journal of Travel Research, 35 (4), 11-15.

Baloglu, S., McCleary, K.W. 1999. A model of Destination Image Formation. Annals of Tourism Research, 26 (4), 868-897.

Barthes, R. 1957. Mythologies. Paris: Editions Seuil.

Begley, 1. 2017. The World's 50 Best Beaches, Ranked, Plus 6 Getaways Millennials Will Love. Forbes, 27/11/2017.

Boyer, M. 2002. El turismo en Europa, de la Edad Moderna al siglo XX. Historia Contemporánea, 25, 13-31.

Buck, Y. 1977. The Ubiquitous Tourist Brochure: Explorations in its Intended and Unintended Use. Annals of Tourism Research, 4 (4), 195-207.

Camprubí, R. Guía, J y Comas, J. 2014. Analyzing image fragmentation in promotional brochures: A case study of two urban destinations. Journal of Hospitality \& Tourism Research, 38 (2), 135-161.

Cirer, J.C. 2012. The beginnings of tourism in Majorca. 1837-1914. Annals of Tourism Research, 39(4), 1779-1796.

Choi, S, Lehto, X.Y., Morrison, A.M. 2007. Destination image representation on the web: content analysis of Macau travel related websites. Tourism Management, 28(1), 118-129.

Crompton, J.L. 1979. An assessment of the image of Mexico as a vacation destination and the influence of geographical location upon the image. Journal of Travel Research, 17 (4), 18-23.

Dann, G. 1988. Images of Cyprus projected by tour operators. Problemy Turystyki, 11(3). 43-70.

Dann, G. 1996. The people of tourist brochures. En SEWYN, T. (ed.) The tourist image. Myths and myth making in tourism. Chichester: Wiley, 61-81.

Davins, A. 1925. Menorca, la isla blanca-azul. Barcelona: Atenas.

Descamps, G., Camprubí, R. 2018. 35 años de carteles turísticos en Cataluña: evolución de la imagen turística catalana del 1980 al 2015. Boletín de la Asociación de Geógrafos Españoles, 79, 2486, 1-25. http://dx.doi.org/10.21138/bage.2486.

Echtner, C., Ritchie, J.R.B. 1991. The Meaning and Measurement of Destination Image. Journal of Tourism Studies, 2 (2), 2-12.

Echtner, C. 2002. The content of third world tourism marketing: a 4a approach. International Journal of Tourism Research, 4(6), 413-434.

Fakeye, P.C., Crompton, J.L. 1991. Image differences between prospective, first-time and repeat visitors to the Lower Rio Grande Valley. Journal of Travel Research, 30 (2), 10-16.

Galí, N., Donaire, J.A. 2003. La imagen a priori de los destinos turísticos monumentales: el caso de Girona. Papers de turisme, 34, 78-97.

Galí, N., Donaire, J.A. 2005. The social construction of the image of Girona: a methodological approach. Tourist Management, 26, 777-785.

Garrod, B. 2009. Understanding the relationship between tourism destination imagery and tourist photography. Journal of Travel Research, 47(3), 346-358.

Gartner, W. C. 1993. Image Formation Process. Journal of Travel \& Tourism Marketing, 2 (2/3), 191-215.

Goodall, B. 1991. Understanding Holiday Choice. En Cooper, C. (ed.). Progress in tourism, recreation and hospitality management. London: Beihaven Press, 58-77.

Gormsen, E. 1997. The impact of tourism on coastal areas. GeoJournal. 1 (42), 39-54.

Govers, R., Go, F.M. 2004. Projected destination image online: website content analysis of pictures and text. Information Technology \& Tourism, 7(2), 73-89.

Gunn, C.A. 1988. Vacationscape: Designing Tourist Regions. New York: Van Nostrand Reinhold (2a. Ed.).

Harvey, D. 1989. The Condition of Postmodernity. Oxford: Blackwell.

Hernández, J. 2008. La imagen de Andalucía. Sevilla: Fundación Centro de Estudios Andaluces.

Hunt, J.D. 1975. Image as a Factor in Tourism Development. Journal of Travel Research, 13, 1-7. 
Hunter, W.C. 2008. A typology of photographic representations for tourism: depictions of groomed spaces. Tourism Management, 29(2), 354-365.

Hunter, W.C. 2016. The social construction of tourism online destination image: A comparative semiotic analysis of the visual representation of Seoul. Tourism Management, 54, 221-229.

Jenkins, O.H. 2003. Photography and travel brochures: the circle of representation. Tourism Geographies, $5(3), 305-328$.

Kolbe, R.H. y Burnett, M.S. 1991. Content-analysis research: An examination on destination images. Journal of Tourism Research, 30, 216-237.

Kotler, P., Haider, D.H., Rein, I. (1994). Mercadotecnia de localidades. México: Diana.

Larrinaga, C. 2015. De las playas frías a las playas templadas: la popularización del turismo de ola en España en el siglo XX. Cuadernos de historia contemporánea, 37, 67-87.

Markwell, K.W. 1997. Dimensions of photography in a nature-based tour. Annals of Tourism Research, 24(1), 131-155.

Markwick, M. 2001. Postcards from Malta: image, consumption, context. Annals of Tourism Research, 28(2), 417-438.

Mansfeld, Y. 1992. From Motivation to Actual Travel. Annals of Tourism Research, 19 (3), 399-419.

Méndez, A. 2017. A la recerca del paradís. Història del turisme de Menorca. Maó: Institut Menorquí d'Estudis, 26-44.

Mercille, J. 2005. Media effects on image: the case of Tibet. Annals of Tourism Research, 32(4), 1039-1055.

Miossec, J.M. 1977. Un modèle de l'espace touristique. L'espace géographique, 1, 41-48.

Morgan, N., Pritchard, A. 2001. Advertising in Tourism and Leisure. Oxford: Butterworth-Heinemann.

Moutinho, 1. 1987. Consumer Behaviour in Tourism. European Journal of Marketing, 21 (10), 3-44.

Nelson, V. 2005. Representation and images of people, place and nature in Grenada's tourism. Geografiska Annaler, 87 b (2), 131-143.

Paül, D. 2018. Characterizing the location of tourist images in cities. Differences in user-generating images (Instagram), official tourist brochures and travel guides. Annals of Tourism Research, 73, 103-115.

Pemple, J. 1987. The Mediterranean Passion. Oxford: Clarendon Press.

Picazo, P., Moreno-Gil, S. 2017. Analysis of the projected image of tourism destinations on photographs: a literature review to prepare for the future. Journal of Vacation Marketing, 1-22.

Poutet, H. 1995. Images touristiques de l'Espagne: de la propagande politique à la promotion touristique. Paris: L'Harmattan.

Pritchard, A., Morgan, N.J. 1995. Evaluating vacation destination brochure images: The case of local authorities in Wales. Journal of Vacation Marketing, 2, 23-38.

Pritchard, A., Morgan, N.J. 1996. Selling the Celtic arc to the USA: a comparative analysis of the destination brochure images used in the marketing of Ireland, Scotland and Wales. Journal of Vacation Marketing, 2(4), 346-365.

Sontag, S. 2002. On photography. London: Penguin.

Towner, J. 1985. The Grand Tour: A Key Phase in the History of Tourism. Annals of Tourism Research, $12,173-189$.

The 50 best beaches in the world. The Guardian, 16/02/2016.

Thurot, J.M., Thurot, G. 1983. The ideology of class and tourism confronting the discourse of advertising. Annals of Tourism Research, 10 (2), 173-189.

Urry, J. 1990a. The consumption of tourism. Sociology, 24(2), 23-35.

Urry, J. 1990b. The Tourist Gaze. London: SAGE.

Uzzell, D. 1984. An Alternative Structuralist Approach to the psychology of tourism marketing. Annals of Tourism Research, 11 (1), 79-99.

Verdaguer, M. 1928. Piedras y viento. Barcelona: Lux.

\section{Notas}

The Guardian (2016), Forbes (2017).

FRONTUR, 2017.

INE. Anuario Estadístico de España 2007.

Recibido:

$27 / 01 / 2019$

Reenviado:

$11 / 06 / 2019$

Aceptado:

$18 / 03 / 2020$

Sometido a evaluación por pares anónimos 